\title{
EM DEFESA DA NOÇÃO DE REDES REFERENCIAIS NA CONSTRUÇÃO DO TEXTO
}

\author{
DEFENDING THE NOTION OF REFERENTIAL NETWORKS IN THE CONSTRUCTION \\ OF THE TEXT \\ Janaica Gomes Matos ${ }^{1}$
}

\begin{abstract}
RESUMO: Nosso artigo se centra na necessidade de rediscutirmos a noção mais clássica em torno das cadeias referenciais, na Linguística Textual e, com base nisto, repensarmos um novo tratamento a conferir sobre o fenômeno, sugerindo chamá-lo de redes referenciais, de modo mais compativel com os pressupostos sociocognitivo-discursivos, na área de estudos da referenciação. Para tanto, apoiamo-nos, principalmente, em obras como a de Cavalcante (2011; 2012), Cavalcante, Custódio Filho e Brito (2014) e Custódio Filho (2011). Nossa proposta é resultante de nossa pesquisa de tese sobre as tessituras de referentes, atendendo aos parâmetros do gênero textual e à construção das recategorizações aplicadas à nota jornalística.
\end{abstract}

PALAVRAS-CHAVE: Redes referenciais; nota jornalística; recategorizações.

ABSTRACT: Our article focuses on the need to rediscuss the more classical notion around referential chains in Textual Linguistics and, based on this, rethink a new treatment to check about the phenomenon, suggesting to call it referential networks, in a way more compatible with the sociocognitive-discursive presuppositions, in the area of reference studies. To do so, we have support mainly in works such as Cavalcante (2011, 2012), Cavalcante, Custódio Filho and Brito (2014) and Custódio Filho (2011). Our proposal is the result of our thesis research on the tessitures of referents, considering the parameters of the textual genre and the construction of the recategorization applied to the journalistic note.

KEYWORDS: Reference networks; journalistic note; recategorization.

\section{Introdução}

A motivação para a elaboração de nosso artigo advém da necessidade de se explicar melhor certas nuances do fenômeno de referenciação que implicam a elaboração de cadeias

\footnotetext{
${ }^{1}$ Mestra em Linguística pela Universidade Federal do Ceará (2005). Docente da Universidade Estadual do Piauí (UESPI). Doutoranda em Linguística pela Universidade Federal do Ceará.
} 
referenciais, também conhecidas como cadeias anafóricas. Assim, buscamos uma nova roupagem ao tratamento desse conceito, propondo a noção de redes referenciais, de modo a atender aos parâmetros do gênero textual e à construção das recategorizações, na confecção de notas jornalísticas.

Por isso, percebemos a necessidade de contemplar, em nossa pesquisa sobre as redes, certos aspectos sociocognitivos que, nos estudos conhecidos sobre as cadeias, não são considerados. Primordialmente, é importante salientar o fato de não estarmos atrelando as redes exclusivamente às expressões referenciais, ou ao emprego de elos coesivos. Isto porque, ao contrário de definições tradicionais sobre as cadeias, que as concebem somente como nexos coesivos, ou ainda, como designações de referentes presas aos encadeamentos superficiais do texto (o que, a nosso ver, sugere o nome "cadeias"), admitiremos, como ponto de partida, que as redes referenciais não devem ser consideradas unicamente pelas formas léxico-semânticas de denominação dos referentes, haja vista os contextos passíveis de determinação de um referente, mediante uma série de indícios que emergem no cotexto para essa construção, conforme alegam Cavalcante, Custódio Filho e Brito (2014).

A par de concepções clássicas sobre as cadeias, na abordagem da referência no texto desde as de nexo coesivo até as chamadas cadeias referenciais - entendemos nós que refletir sobre a formação dessas tessituras ou redes referenciais significa ultrapassar a análise do sistema léxico-gramatical da língua, muito embora a organização desse sistema tenha a devida influência sobre a análise sociocognitivo-discursiva da referência. Advogamos, pois, em defesa da observação de uma multiplicidade de fatores de construção do referente, sob pena de nos cerrarmos em critérios ineficientes para examinar, em profundidade, as formas de elaboração e compreensão do texto. Para tanto, à luz da referenciação, discutimos o tratamento dado às cadeias referenciais e explicamos os fundamentos da noção de redes referenciais, apresentando nossa análise do fenômeno sob tais moldes, no gênero nota jornalística.

\section{A área da referenciação: as cadeias referenciais e a perspectiva da (re)construção intersubjetiva do referente}

A referenciação é uma atividade que permeia a comunicação dos indivíduos em geral, abrigando uma gama de processos inscritos como atividades de construção de referentes/ objetos de discurso depreendidos, por vezes, por expressões linguísticas, ou mais propriamente, por expressões referenciais, conforme Cavalcante (2012). A partir desta noção, 
passa-se à verificação de que tais expressões não servem apenas como formas de coesão, pois revelam atos permeados de outras funções, que não apenas a simples estruturação de um texto.

Consequentemente, a incrível plasticidade das categorias de referência é, sem dúvida, atestada nas teias de referentes, que colaboram para sua recategorização e tendem a se amoldar aos propósitos dos gêneros e sequências textuais (cf. RONCARATI, 2010; KOCH E ELIAS, 2010; SOUSA, 2013), ao mesmo tempo em que fornecem grande vazão aos direcionamentos argumentativos pretendidos por seus produtores. Portanto, mais do que simplesmente referir, a natureza da referência também se encontra a serviço dos mais diferentes propósitos comunicativos dos falantes, ao assinalarem pontos de vista, contradições, negociações, formas de organização do texto, reorientações argumentativas, efeitos estilísticos e diversas funções discursivas de outros tipos, segundo assevera Ciulla e Silva (2008).

De um modo mais geral, tal como tem sido tratada na literatura da referenciação, a cadeia referencial constrói-se quando os referentes se introduzem e se desenvolvem no texto, podendo ser mencionados na continuidade do texto, ou podendo servir de base para a aparição de mais outro (s) referente (s). Logo, o critério privilegiado nesta concepção é o da menção das expressões que denominam os referentes, o que, conforme veremos adiante, situa-se numa primeira tendência de estudos da referenciação.

Já a recategorização é um fenômeno dinâmico, resultante de tal processo de tessitura dos referentes, pois significa as mudanças por que passa o referente no discurso; mudanças essas que serão abordadas no presente trabalho, através do que chamamos não mais de cadeias, e sim de redes referenciais. Conforme certificam Cavalcante, Custódio Filho e Brito (2014, p. 156), "Em todo texto, o locutor constrói a referência com base numa interpretação do mundo real, recategorizando a informação precedente ao acrescentar novas predicações, disponíveis, em diferentes graus, no conhecimento das pessoas, à medida que transcorre a interação". É isso justamente o que ocorre nas redes referenciais, pois à medida em que se entrelaçam no texto, os objetos de discurso travam uma multiplicidade de relações entre si e com a aparelhagem conceitual dos interlocutores do texto capazes de estabelecer a manutenção de certos referentes e de promover a aparição e o processamento de outros simultaneamente, adicionando traços e características aos objetos continuamente, no universo textual-discursivo. Eis por que as recategorizações constituem estratégias textuais e cognitivas que ocorrem a todo instante nos processos referenciais, durante a constituição das redes. 
No que toca a um estudo mais meticuloso acerca dessa tessitura de referentes, na constituição dos textos, muito pouco se disse nesta nova tendência da referenciação, apesar da grande relevância deste fenômeno para sinalizar a recriação do referente e, além disso, para construir o gênero textual em que vem situada. Em razão disto, uma noção de tessitura de referentes que englobe aspectos sociais e cognitivos de sua construção ainda não foi efetivamente proposta pelos autores até hoje. A esse propósito, vejamos algumas postulações e análises existentes sobre as cadeias referenciais, na perspectiva da referenciação.

\subsection{A abordagem conceitual das cadeias referenciais na referenciação}

Sob tais pressupostos da referenciação, algumas noções de cadeia foram adotadas por alguns autores, os quais falam apenas de modo breve sobre o fenômeno; enquanto outros pesquisadores analisaram-no sob certas facetas. Em Marcuschi (2001), o autor aborda, rapidamente, o conceito de cadeias referenciais com o papel de sequenciar estados de coisas e entidades, de modo que quase sempre se desenvolvem cadeias lacunosas, exigindo conhecimentos comuns, partilhados, situativos para preenchimento destes espaços no texto e, por conta disso, o autor acentua o papel das anáforas indiretas enquanto estratégia sistemática de suprir lacunas lexicais (abordaremos as anáforas indiretas no item que trata dos processos referenciais segundo Cavalcante $(2011,2012))$. E novamente o autor menciona as cadeias, em Marcuschi (2008), ao analisar a relação entre referenciação e coerência, considerando que um texto se constrói e progride com base nos processos de progressão referencial e tópica. Progressão referencial diz respeito à introdução, identificação, preservação, continuidade e retomada de referentes textuais, correspondendo às estratégias de designação de referentes e formando o que o autor denomina de cadeia referencial.

Vejamos o que diz Cavalcante (2011) sobre a confecção dos referentes no texto, na construção de cadeias ou elos referenciais sob o prisma da referenciação:

Essa tessitura de elos interligados, coesos, que não se costuram exclusivamente pelo que está explícito no cotexto, senão também pelo que se encontra implícito na memória discursiva ${ }^{2}$ e que se descobre por inferências, é a condição básica para que uma unidade de coerência se forme na mente de enunciadores e coenunciadores (cf. CAVALCANTE, 2011, p. 59).

\footnotetext{
${ }^{2}$ Por memória discursiva se quer dizer "um conjunto de representações que os interlocutores constroem de si mesmos, dos temas, de conhecimentos socioculturais compartilhados, de suas finalidades argumentativas quando interagem por meio de um texto". (cf. CAVALCANTE, CUSTÓDIO FILHO E BRITO, 2014, p. 153)
} 
Sobre este fenômeno, Koch e Elias (2010) apontam para o fato de que, quando remetemos seguidamente a um mesmo referente, ou a elementos estreitamente ligados a ele, formamos cadeias anafóricas ou referenciais. Esse movimento de retroação a tais elementos constitui um princípio de construção textual, já que praticamente todos os textos possuem uma ou mais cadeias referenciais. Segundo Koch e Elias (2010), os elementos constituintes destas cadeias são responsáveis por efetuar uma série de funções importantes para a construção dos sentidos textuais, como a recategorização, a qual vai acrescentando ou alterando características e propriedades dos referentes, por meio de traços diferentes que lhe vão sendo atribuídos, cada um revelando uma face diferente do mesmo objeto. Logo, afirmam as autoras que este é um meio poderoso para estabelecer a orientação argumentativa do texto.

Já a propriedade flexível das redes na constituição dos gêneros e também nas sequências textuais encontra respaldo em pesquisadoras como Koch e Elias (2010), Roncarati (2010) e Sousa (2013). As autoras Koch e Elias (2010), por sua vez, relacionam as cadeias aos elementos constituintes das sequências textuais ${ }^{3}$, de maneira a declarar que, na sequência narrativa, cada cadeia será formada em torno dos elementos tempo, espaço, protagonista, antagonista e elementos ligados aos personagens, ao passo que, nas demais sequências, haverá pelo menos uma cadeia ligada ao referente central tratado no texto. Não obstante isso, essas autoras não descrevem, sistematicamente, como estas teias de referência se desenvolvem em torno dessa associação com as sequências textuais e gêneros do discurso, na progressão (recategorização) textual.

Ao passo que Roncarati (2010), ao analisar uma variedade de textos orais e escritos, alega, sob bases empíricas, que os formatos das cadeias, bem como as estratégias de referenciação as quais as conformam, tendem a se adaptar aos mais diversos gêneros e sequências textuais em que se inserem. A autora, apesar de contemplar as recategorizações flagradas no movimento das tessituras referenciais, só as considera sob a condição de homologarem, ao final da cadeia, as predicações e atributos imputados ao referente ao longo do texto.

Em perspectiva funcionalista e discursivo-textual da gramática, a dissertação da pesquisadora Sousa (2013) demonstra as evidências em torno da influência das sequências textuais narrativa, descritiva e argumentativa, sobre os tipos de cadeias de referentes, na composição do gênero romance literário. Sousa (2013) analisa os preenchimentos formais

\footnotetext{
3 Jean-Michel Adam (2011), autor que originou a conceituação de "sequências textuais", define-as como um dos mecanismos de textualização, que consiste num conjunto de proposições cognitivamente estabilizadas enquanto recurso composicional que atravessa todos os gêneros. São elas, a saber: a sequência narrativa, a descritiva, a argumentativa, a explicativa, a dialogal e a injuntiva; porém esta última foi excluída pelo autor.
} 
(sintagma nominal, pronome, zero Ø) operados na referenciação e sua relação com os modos de introdução e de manutenção dos objetos de discurso, observando também os casos de recategorização nestes moldes. Então, na sequência narrativa, observou-se o modo de referência e identificação das personagens. Na sequência descritiva, o foco se deu sobre a construção dos elementos espaciais das cenas descritas; quanto à sequência argumentativa, observou-se os elementos usados na construção do ponto de vista do enunciador.

Enfim, de certa forma, esses conceitos e análises representam avanços, na medida em que uns se movem em direção a aspectos mais cognitivos, como Marcuschi (2008) e Cavalcante (2011), enquanto outros tendem a reforçar os pressupostos concernentes aos condicionamentos genéricos sobre a montagem das teias referenciais, tais como as obras de Roncarati (2010), Koch e Elias (2010) e Sousa (2013). Porém, falta-lhes um novo tratamento das cadeias que abarque esses aspectos, o que nos leva a sugerir a abordagem da qual agora falaremos.

\section{O que significa a noção de redes referenciais?}

A par das pesquisas empreendidas em torno das cadeias, com uma maior preocupação em se descrever a forma das expressões que as constituem, que é o caso de análises formalistas, como as da coesão, e até de estudos de referenciação em perspectiva também atrelada ao cotexto ${ }^{4}$, sugerimos a abordagem conceitual e analítica em favor da noção de redes referenciais. Assim, preferimos chamar as cadeias de redes referenciais - como metáfora de produtiva utilização nas Ciências Humanas - porque julgamos que tanto a denominação quanto a noção conceitual de cadeias se vincula, não raro, a visões mais restritas do fenômeno.

Buscamos analisar as redes referenciais numa perspectiva sociocognitivodiscursiva. Segundo o que observamos, as redes referenciais são entrelaçamentos de sentidos na construção dos referentes, os quais mantêm uma diversidade de relações entre si e que se adaptam, funcionalmente, aos modos de constituição dos textos. Dessa forma, tais redes são formadas por nódulos ativados pelo contexto, estabelecendo uma série de associações de várias naturezas, funcionando como links, ou modos de conexões entre os referentes, os quais

\footnotetext{
${ }^{4}$ Referimo-nos aqui à primeira tendência dos estudos de referenciação, de acordo com Cavalcante (2011) e Custódio Filho (2011), que privilegia a menção das expressões referenciais, diferentemente da segunda tendência da referenciação, que considera, primordialmente, a maneira por que os vários elementos que participam da configuração textual (superfície linguística, aparato cognitivo, aspectos sócio-históricos e circunstanciais) são acionados para a construção de referentes.
} 
são todos interligados na construção e manutenção da coerência. Neste mesmo pensamento, as recategorizações que atuam nessas redes são avalizadas não apenas por tipos pontuais e restritos a certas unidades linguísticas, mas também por uma infinidade de indícios contextuais, resultantes de uma visão sociocognitiva sobre os processos de referência.

Em razão do que teoricamente aventamos até aqui, convém sintetizar algumas características que desejamos abarcar na noção de redes, diferentemente das cadeias de referentes:

as construções das redes de referentes não decorrem somente da edificação das unidades lexicais que os designam, mas também se constituem de diversos fatores contextuais de construção dos referentes chegando a dispensar, em frequentes casos, a explicitação da própria nomeação das entidades, vista sob uma superfície textual em linearidade;

$\checkmark \quad$ com o fim de observarmos o funcionamento das redes na construção dos sentidos do gênero nota jornalística, adaptamos a análise de Figueiredo (2003) (cujas bases remontam ao modelo CARS de Swales (1990)) sobre a construção retórica dos subgêneros da nota jornalística. Como resultado de nossa pesquisa, declaramos haver algum tipo de previsibilidade entre certas redes referenciais e o papel retórico que elas ocupam em modelos prototípicos de notas jornalísticas;

as relações entre os referentes não são apenas léxico-semânticas, mas podem ser diversas, sobretudo, sociocognitivas e discursivas, de modo que, nestas duas últimas, situa-se a essência de nossa abordagem evolutiva do referente construído pelas redes, com base em Bonomi (1994) e principalmente em Custódio Filho (2011), os quais sugerem que as relações entre os referentes intervêm nessa recategorização. Custódio Filho (2011), por sua vez, elabora o esquema das quatro (4) etapas sobre os modos de apresentação e de continuidade (recategorização) referencial, o qual utilizamos na investigação do percurso evolutivo que tais redes tomam.

$\mathrm{Na}$ seção que virá, demonstraremos nossa forma de análise, que abrange os pressupostos acima assentados.

\section{1. Como descrevemos as redes referenciais}

Em nossa pesquisa de tese sobre as redes referenciais, analisamos um corpus de quarenta (40) exemplares de notas jornalísticas em diversos jornais e revistas on-line. A nota jornalística é caracterizada como pequena notícia destinada à informação rápida (cf. manual da Folha de São Paulo, 1998), a qual consideramos mediante apenas dois tipos de subgêneros: 
a nota noticiosa e a nota opinativa, conforme a nossa adaptação da proposta de Figueiredo $(2003)^{5}$.

Vejamos um exemplo de cada subgênero e de como ocorre o funcionamento das redes na construção do gênero e também das recategorizações, a começar pelo subgênero noticioso:

(1) Move 1: Identificar a nota - passo 2B: Identificar pontos mais salientes Janaína Paschoal se impõe contra Lindbergh

"Como petistas têm vassalos, e não orientandos, exigem que os outros se ajoelhem"

Passo 1A: Ilustrar a nota com fotografia ou desenho ou gráfico

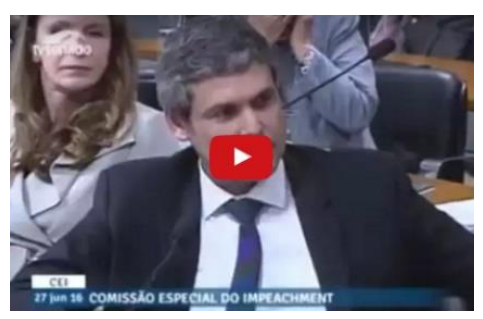

Lindberg x Janaína

(Movimento 2: Sumarizar a nota - passo 2A: Citar o elemento desencadeador do fato) Janaína Paschoal (passo 1: citar o fato) se impôs mais uma vez contra (passo 2B: citar o elemento afetado pelo fato) Lindbergh Farias (PT-RJ) (passo 2C: Situar o fato) na comissão do impeachment. (passo 2D: Citar causa/motivo do fato) $\mathrm{O}$ senador petista havia dito que estranhou o fato de o juiz que decretou a prisão de Paulo Bernardo [grifo do autor] ser orientado em pesquisa na USP pela coautora do pedido de impeachment contra Dilma Rousseff.

(Movimento 3: agregar informações complementares - passo 1A: Apresentar o fato) Na sessão desta segunda-feira (27), a advogada rebateu a insinuação de "Lindinho" (passo 1L: Relatar posicionamento do opinante) alegando que o juiz toma suas decisões de acordo com a sua própria consciência.

(Passo 2A: Comentar posicionamento de opinante) Para arrematar tamanha obviedade e mostrar que o PT tenta medi-la com a régua do partido, Janaína saiu-se com uma

\footnotetext{
${ }^{5}$ Figueiredo (2003) aponta, originalmente, como três (3) os subgêneros da nota jornalística: a nota noticiosa, a nota comentário e a nota comentário relatado. Contudo, consideramos apenas dois (2), pelo fato de os dois últimos tipos citados possuírem grande semelhança funcional e estrutural.
} 
frase memorável: (Passo 2B: apresentar argumento que sustenta a opinião) "Como os petistas têm vassalos, e não orientandos, eles exigem que os outros se ajoelhem diante deles.

Assista”. (Veja.com, por Felipe Moura Brasil, 27/06/2016)

No presente texto, que mescla, retoricamente, a notícia e a opinião, destacam-se dois referentes na estrutura composicional, porém um construído em sentido contrário ao do outro: um deles é Janaína Paschoal e o outro, Lindberg Farias. Em função ilustrativa, a imagem ${ }^{6}$ que aparece no vídeo é a de Lindberg, cuja fisionomia julgamos que tende a confirmar a ideia de um contexto de tensão. O repórter focaliza Lindberg como um elemento afetado pelo fato (elemento sobre o qual o fato incide), delegando à Janaína uma postura de desencadeador do fato (componente que acarreta a ação do fato central da nota).

No início do texto, a expressão conotadora de rivalidade Lindberg x Janaína, bem como a construção Janaína Paschoal se impôs mais uma vez contra Lindbergh Farias, fortalecem esse efeito de sentido, pois ambos se revelam, assim, em uma situação discursiva de oposição. Note-se que Janaína vai sendo ideologicamente remodelado de modo apreciativo, em detrimento da construção pejorativa de Lindberg. A figura positiva de Janaína sobressai-se através de certas marcas textuais denotando o próprio posicionamento do jornalista em seu favor, uma vez se resgatando os eventos em torno do impeachment da presidente da República do Brasil, no ano de 2016, em nosso conhecimento sobre o episódio.

Desse modo, além das propriedades atribuídas como a advogada e coautora do pedido de impeachment contra Dilma Rousseff, juntamente aos verbos indicadores de força e de ação, rebateu e arrematar, além das qualificações do juiz, também positivamente vinculado a ela (o juiz toma decisões de acordo com sua própria consciência, ou ainda, a construção indireta de que o juiz é um orientando, e não um vassalo), sem esquecer as anáforas indiretas a respeito de Janaína, tamanha obviedade e uma frase memorável, que realizam com igual vigor o papel dessa avaliação. Tais referentes representam, sem dúvida, uma posição de relevo nessa nota, conforme o destaque dado à opinião da advogada no movimento retórico 1 , de identificação da nota.

Em contrapartida, detectamos que tais anáforas causam um efeito de embate a uma avaliação positiva de Lindberg no contexto enunciativo. Como suporte, afluem então certos elementos de referência que revelam, principalmente, marcas de desqualificação do partido político PT, ao qual pertence Lindberg. Por exemplo, os petistas têm vassalos, e não

\footnotetext{
${ }^{6}$ Muito embora não nos ocupemos, pontualmente, das semioses visuais ou de outras questões multimodais na construção das redes, não poderemos aqui ignorar seu papel na construção verbal do referente.
} 
orientandos, eles exigem que os outros se ajoelhem diante deles, mesmo em referência indireta, é pejorativa em relação a Lindberg e ao PT. Ao mesmo tempo em que, nas entrelinhas, é um traço oposto à Janaína e ao juiz, por significar, segundo a construção do elemento opinante, que Janaína não possui vassalos, e sim orientandos, que agem por consciência própria, e não sob a régua do partido do $P T$. Por isso, não é à toa que o repórter põe em negrito a nomeação de um elemento ligado à causa do fato, a prisão de Paulo Bernardo, o qual deve ser recuperado, intercognitivamente, também como um integrante do PT, além da presidenta Dilma Rousseff, graças ao nosso conhecimento compartilhado.

Por fim, havemos de lembrar que a tamanha obviedade - significando que tal posicionamento foi absolutamente claro, segundo Janaína e que foi endossado pelo repórter possui como âncora o fato alegado pelo senador petista, o qual foi reconstruído pelo encapsulamento ligado à causa desse fato, a insinuação de "Lindinho". Daí a carga altamente depreciativa do sufixo -inho anexo ao nome próprio. Portanto, a insinuação de "Lindinho" veio ao encontro da opinião de Janaína.

Em resultado, aplicando-se o esquema de Custódio Filho (2011), as recategorizações tendem a confirmar o estado inicial dos referentes como figuras antagônicas no texto, acrescentando-lhes dados e características que acentuam essa relação discursiva, de modo que uma construção referencial desfavorece a outra.

Vejamos outro exemplo, desta vez, com o subgênero opinativo da nota:

(2) TST (Movimento 1 - Identificar a nota: Passo 2A - categorizar a nota) Modernos escravistas_(Passo 2B - identificar pontos mais salientes)

(Movimento 2 - Introduzir comentário: Passo 1 - identificar o opinante)

Maior autoridade da Justiça trabalhista no Brasil, o presidente do TST, João Dalazen, (Passo 2A - Relatar posicionamento) aplaude a proposta de emenda constitucional que equipara os direitos dos domésticos aos dos demais assalariados, em exame no Legislativo. (Movimento 3 - Fundamentar comentário: passo 1A - Relatar argumento(s) que sustenta(m) o posicionamento) "O País não pode ter mão de obra de primeira e de segunda classe. Quem diz que a PEC trará desemprego age como os senhores de terras no século XIX, resistentes ao fim da escravidão”. (Portal IstoÉ, por Ricardo Boechat, 30/11/2012)

Inicialmente, a introdução obscura de modernos escravistas, que sugere alguma relação discursiva com TST, vai dando lugar, gradativamente, à ideia de desigualdade 
trabalhista pautada no conceito de escravidão, conforme o posicionamento defendido pelo opinante. Tal posicionamento se constrói mediante uma série de pistas, tais como a proposta de emenda constitucional que equipara os direitos dos domésticos aos dos demais assalariados (fato central que ancora a discussão), mão de obra de primeira e de segunda classe (elementos do fato) e os senhores de terras no século XIX, resistentes ao fim da escravidão (elemento ligado aos argumentos que sustentam o posicionamento), todos dotados de juízos de valor.

Igualmente de forma valorativa, a expressão que apresenta o opinante, maior autoridade da Justiça Trabalhista no Brasil, o presidente do TST, João Dalazen, explica a sigla TST posta no título, numa associação que se descobrirá contrária a modernos escravistas. Tal leitura foge à disposição linear das expressões no texto, o que justifica uma visão de construção referencial não presa a um cotexto. Assim sendo, o imbricamento entre os referentes vai tecendo as relações discursivas entre eles e a entidade modernos escravistas, juntamente com outros indícios contextuais, fazendo a costura do texto e ajudando o locutor a construir seu projeto de dizer.

De acordo com isto, a entidade focalizada nada mais é do que quem diz que a PEC trará desemprego, que se compara aos senhores de terras no século XIX, resistentes ao fim da escravidão, isto é, aquele que se opõe ideologicamente a PEC enquanto instrumento de libertação do trabalho escravo, funcionando, pois, como uma espécie de contra-argumento como peça-chave para a sustentação do ponto de vista do opinante.

Mais uma vez, a proposta de Custódio Filho (2011) nos mostra que o percurso percorrido pelo referente, neste caso, modernos escravistas, ocorre por acréscimo e confirmação, pois há uma torrente de modificações causadas pelos constantes acréscimos de sentidos a esse referente, bem como a homologação de um sentido negativo a ele atribuído, relacionado à escravidão trabalhista. Nisto observamos a interveniência de outros referentes sobre as recategorizações do referente em questão, o qual se reconstruiu com base nessas relações, dentro de um contexto sociocognitivo de implicitude, não prontamente pontuado por sua apresentação explícita no começo do texto.

\section{Considerações finais}

Enfim, propusemos uma noção de rede referencial de sorte a atender às imposições do gênero e das evoluções referenciais. De acordo com esse propósito, sugerimos a existência de certas categorias de redes construídas com base em elementos de construção prototípica dos 
subgêneros da nota jornalística, compreendendo que os referentes construídos são, antes de tudo, mergulhados em contextos, tais como o da sociocognição e do gênero textual, e nestas condições, encontram seu papel, que, por outro lado, também se encarrega de transformar os referentes continuamente no texto, inclusive também em benefício argumentativo do produtor do texto; neste caso, dos jornalistas, principalmente.

\section{REFERÊNCIAS}

ADAM, Jean Michel. A Linguística Textual: introdução à análise textual dos discursos. São Paulo: Cortez, 2011.

ANTUNES, Irandé. Aspectos da coesão do texto: uma análise em editoriais jornalísticos. Recife: Editora da UFPE, 1996.

BONOMI, Andrea. Lo spirito dela narrazione. Milão: Bompiani, 1994.

CAVALCANTE, Mônica. Expressões referenciais - uma proposta classificatória. In: Caderno de estudos linguísticos. Campinas, n. 44, p. 105-118, jan/jun 2003.

- Referenciação - sobre coisas ditas e não-ditas. Fortaleza: Edições UFC, 2011.

Os sentidos do texto. São Paulo: Contexto, 2012.

CAVALCANTE, Mônica; CUSTÓDIO FILHO, Valdinar; BRITO, Mariza Angélica. Coerência, referenciação e ensino. SP: Cortez, 2014.

CORBLIN, Francis. Les formes de reprise dans le discours - anaphores et chaines de référence. Rennes: Presses de l'Université de Rennes, 1995.

CIULlA E SILVA, Alena. Os processos de referência e suas funções discursivas: o universo literário dos contos. 201p. Tese (Doutorado em Linguística). Universidade Federal do Ceará, Fortaleza, 2008.

CUSTÓDIO FILHO, Valdinar. Múltiplos fatores, distintas interações: esmiuçando o caráter heterogêneo da referenciação. 270 f. Tese (Doutorado em Linguística). Universidade Federal do Ceará, Fortaleza, 2011.

FIGUEIREDO, Lisette Fernandes. A nota jornalística no Jornal do Brasil: um estudo do gênero textual e de sua função no jornal. 133f. Dissertação (Mestrado em Ciências da Linguagem). Universidade do Sul de Santa Catarina, Tubarão, 2003.

FOLHA de S. Paulo. Novo Manual da redação. 8. ed. São Paulo: Folha de S. Paulo, 1998.

HALLIDAY, Michael; HASAN, Ruqayia. Cohesion in English. London: Longman, 1976.

KOCH, Ingedore. Introdução à Linguística Textual: trajetória e grandes temas. São Paulo: Martins Fontes, 2004.

KOCH, Ingedore; ELIAS, Vanda Maria. Ler e escrever: estratégias de produção textual. São Paulo: Contexto, 2010.

MARCUSCHI, Luiz Antônio. Anáfora indireta: o barco textual e suas âncoras. In: Revista Letras, n. 56, 2001, p.217-258.

2008.

. Produção textual, análise de gêneros e compreensão. São Paulo: Parábola,

RONCARATI, Cláudia. Cadeias do texto: construindo sentidos. São Paulo: Parábola, 2010. SOUSA, Luciana Ribeiro de. O estabelecimento da cadeia referencial em português: uma análise em diferentes sequências textuais. 172 p. São Paulo, Dissertação (Mestrado em Letras), Universidade Presbiteriana Mackenzie, 2013. 
SWALES, John. Genre analysis: english in academic and research settings. New York: Cambridge University Press, 1990.

Recebido em 31/03/2018. Aceito em 06/06/2018. 